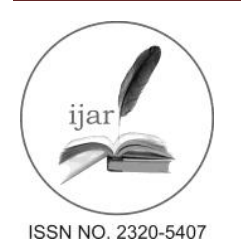

Journal homepage:http://www.journalijar.com

Journal DOI:10.21474/IJAR01

INTERNATIONAL JOURNAL

OF ADVANCED RESEARCH

RESEARCH ARTICLE

\title{
COMPARISON OF STRENGTH AND SPEED BETWEENKHO-KHO AND KABADDI MALE PLAYERS.
}

\author{
Sudhir k r. \\ Guest Lecturer in Physical Education,College of Co-Operation Banking and Management,Kerala Agricultural \\ University, Vellanikkara.
}

\section{Manuscript Info}

Manuscript History:

Received: 22 April 2016

Final Accepted: 17 May 2016

Published Online: June 2016

Key words:

Strength, Speed, Kho-Kho,

Kabaddi.

*Corresponding Author

\section{Abstract}

The purpose of the study was to compare the physical fitness variable of Kho-Kho and Kabaddi Players. To fulfill the objective of the study 25 KhoKho and 25 Kabaddi male players of Calicut University were selected who have participated at minimum inter collegiate level of Calicut University. The data were collected in different coaching camps organized by the colleges of Calicut University. The age of the selected subjects ranged from 19 to 25 years. (Standing Board Jump and 60 yard dash tests) were used to measures the selected physical fitness variables of the players. In order to analyze the data t-test was used to analyze the data and investigator observed the significant different between Kho-Kho and Kabaddi players.

Copy Right, IJAR, 2016,. All rights reserved. Copy Right, IJAR, 2016,. All rights reser.ed.

Sudhir k r.

\section{Introduction:-}

The modern scientific age, in every field of human endeavor systematic, objective and scientific procedures are followed in accordance with the principles based on experience, under-standing and application of scientific knowledge. The field of games and sports has been made possible due to research, experimentation and scientific knowledge in games and sports. An erroneous notion is prevalent among a sizeable section of people in India that sportsperson in general are less intelligent and less alert than non-sportsperson. They think that much of the physical energy of a sportsperson is spent in his sports pursuits. This drains not only his physical energy but also makes him mentally dull. Consequently, his intelligence and mental ability suffer. They, therefore, are of the opinion that the time develop to sports and games on the plane field is a waste in terms of energy loss and of times, which could be more usefully employed in other(i.e. academic) gainful activity.

Psychological factors have a significance effect on an athlete's capacity for training and motivation for competition. Sportsperson of a certain psychological type may be more predisposed to injury. Sports coaches most recognize this characteristic. Factor that are generally believed to influence sports performance include aggression, motivation, anxiety, concentration, self- confidence, emotional state and pain tolerance. With the help of sports psychologist's personality profile of each player may be prepared which may help the trainer in the training camps. The researcher, therefore, has made an attempt to study whether a physically fit person is intelligently fit, since physical education supposedly contributes to the physical as well as mental aspect of the personality. We, the Indians are very much concerned with the performance and status of the sportsperson at deferent levels. But, the performance is final output and the status includes various other aspects in addition to the performance. In the world of sports, every participating individual and spectator generally, eye to the positioned athletes and they also become in the main linelight in the field of sports. The selectors at various levels generally considered the performance in the trial and qualifying competitions, whereas, the physical fitness basis most of the time as ignored variable. The performance at high level or outstanding performance is based upon the foundation of the athlete, which should also be strong and potential. The foundation of sportsperson starts from his initial development phase. The developmental stage starts with the 'teen age' period. The teen age ranged 13 to 19 years. The teen agars generally fall at school and college going category. So, investigator concerned treated the research study on school and college going male students. The basis of performance may be mainly considered on physical fitness variables and other variables depending upon the 
requirement.

\section{Review of related literature:-}

Gupta et al. (2002) ${ }^{[2]}$ conducted a study of the physical fitness, spinal mobility and flexibility in footballers. The study deals with physical fitness spinal mobility, and flexibility of 95 footballers of national and inter-university levels. The player's performances were competed with adequate controls. Three physical fitness tests vez, sit-ups standing broad jump and shuttle run, anterior and lateral spinal flexion and spinal extension were conducted on all the subjects. The results of this study indicated a greater physical fitness in footballers.

RUDI M, et.al, (2001) ${ }^{[1]}$ A total of 146 professional rugby league football players, contracted to 2 teams competing in England $(n=45)$ and Australia $(n=101)$, participated in this study. All players completed the following series of physical fitness performance tests: 1 repetition maximum squat and bench press, 15- and 40-m sprint, agility run, 5minute run for distance, 60-second sit-up, 30- second plyometric push-up, and measurement of body weight and subcutaneous skinfold (4 sites). Analysis of variance with a criterion $\alpha$ level of $p<0.05$ was used to determine if any significant difference could be found when grouping players into 3 different positional categories typically identified in the sport. There were a number of significant differences with respect to test results between categories, and this was apparent for all 3 systems of categorization. On the basis of these findings, we recommend that to more efficiently structure the physical fitness training of players, the players should be grouped either according to the 2 broad positional categories of forwards or backs or according to the 4 categories of forwards, distributors, adjustable, and outside backs. Grouping players according to the 9 specific positions played on the team is not warranted.

\section{Objectives of the Study:-}

The proposed objectives of the present research were follows.

1. To study the Physical fitness components of Kabaddi players.

2. To study the Physical fitness components of Kho-Kho Players.

3. Comparison of the Physical fitness components of KABADDI and KHO-KHO players.

\section{Significance of the Study:-}

The study will be of great interest to all sports lovers of the nation. It will also be useful to the society in general and Kabaddi and Kho-Kho players in particular, we will find it more beneficial to: -

1. It will be provide an opportunity to give suggestions for the promotion of Kabaddi and Kho-Kho.

2. It would serve as a ready reference to the players, coaches and officials to get any information regarding to the game of Kabaddi and Kho-Kho.

3. Being a storehouse of latest information it will serve as a stepping-stone for further researchers.

\section{Hypothesis of the study:-}

There exists no significant difference between Physical fitness components of Kabaddi and Kho-Kho male players.

\section{Delimitation of the study:-}

The present study was delimited on the following aspects such as:

1. Only 50 Male (25 Kabaddi and 25 Kho-Kho) students were considered.

2. The age of the subjects were ranged from 19 to 25 years.

3. The physical fitness components i.e.-strength, agility, speed, and endurance was considered for the present study.

4. Only those male subjects of Calicut University were selected who have participated at minimum inter collegiate level of Calicut University

\section{Method and Procedure:-}

Selection of the Subjects:-

The subjects were selected in following basis:

1. He should be male student.

2. He should attain the age of 19 years and not more than 25 years.

3. He should be studied in Calicut University. 


\section{Criterion Measures:-}

The criterion measures were used to collect the data in a deal and systematic way to record in a correct unit and style for each test item.

1. Explosive leg strength was measured by Standing Broad Jump test and scores were recorded in centimeters.

2. Speed was measured by 60 Yards Dash and time was recorded to the nearest $1 / 100$ of a second with the help of digital stopwatch.

\section{Statistical Techniques Used:-}

For the present study, the mean value, standard deviation, ' $t$ ' test were applied to analyze the data, different steps in ' $t$ ' test were used and the final conclusions was drawn and it was also compared with the significant value at 05 level of confidence with 99 degree of freedom. The utilization of mean values, standard deviation and ' $t$ 'test were made according to the requirement of the present study as per the statistical technique.

\section{Results and Discussion:-}

Table 8.1:- Comparison of Strength Component of Kabaddi and Kho-Kho Male Players in Standing Broad Jump.

\begin{tabular}{|c|c|c|c|c|c|c|c|}
\hline \multirow{2}{*}{ Variable } & \multicolumn{2}{|c|}{ Kabaddi } & \multicolumn{2}{|c|}{ Kho-Kho } & \multirow[t]{2}{*}{ SEd. } & \multirow[t]{2}{*}{ t-ratio } & \multirow{2}{*}{$\begin{array}{l}\text { Level of } \\
\text { significant }\end{array}$} \\
\hline & Mean & S.D & Mean & S.D & & & \\
\hline $\begin{array}{l}\text { Strength (Standing } \\
\text { Broad Jump) }\end{array}$ & 2.18 & .15 & 2.11 & .076 & .038 & 2.018 & Significant \\
\hline
\end{tabular}

*Significant at .05 level

The mean score (2.18 \pm .15) of the strength component of physical fitness of Kabaddi players is high than the mean

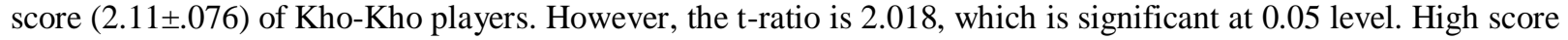
better strength. It means that Kabaddi players have better strength of physical fitness than the Kho-Kho players.

Therefore, the null-hypothesis of significant difference in the level of strength of Kabaddi and Kho-Kho players will be rejected.

Table 8.3: Comparison of Speed Component of Kabaddi and Kho-Kho Male Players

\begin{tabular}{|c|c|c|c|c|c|c|c|}
\hline \multirow{2}{*}{ Variable } & \multicolumn{2}{|c|}{ Kabaddi } & \multicolumn{2}{c|}{ Kho-Kho } & SEd. & t-ratio & $\begin{array}{c}\text { Level of } \\
\text { significant }\end{array}$ \\
\cline { 2 - 5 } & Mean & S.D & Mean & S.D & & & $\begin{array}{c}\text { No } \\
\text { Significant }\end{array}$ \\
\hline $\begin{array}{c}\text { Speed (60 yards } \\
\text { dash) }\end{array}$ & 7.69 & .54 & 7.44 & .46 & .134 & 1.835 & \\
\hline
\end{tabular}

*Significant at .05 level

The mean score (7.69 \pm 0.54$)$ of the Speed component of physical fitness of Kho-Kho players is high than the mean score (7.44 \pm 0.46$)$ of Kabaddi players. However, the t-ratio is 1.835 , which is no significant at 0.05 level. High score better speed. It means that Kho-Kho players have better speed of physical fitness than the Kabaddi players.

Therefore, the null-hypothesis of significant difference in the level of Speed of Kabaddi and Kho-Kho players will be accepted.

\section{Conclusion:-}

On the basis of the analysis of data the Kho- Kho players were having better mean values among speed than Kabaddi male players. Kabaddi players were having better mean values among strength than the Kho-Kho male players

\section{References:-}

1. Dhayanithi R, Ravi Kumar P. Continuous and Alternates pace endurance Methods and their effects on training and determining on selected physical and Determining on selected physical and psychology variables among boys. Research Bi-annual for movement 2002; 19(1):16.

2. Esther $\mathrm{H}$ et al. The effect of age on physical fitness of deaf elementary school children. Pediatric exercise science 2007; 19:267-278.

3. Gaurav V, Singh A, Singh S. A study of physical fitness variables among baseball players at different level of achievement scientific. Journal in sports and exercise 2011; 7(2):34-38. 
4. Bouchard C, Shepherd RJ. Physical activity, fitness and health: The model and Key concepts In: C Bouchard, RJ Sheppard, T. Stephens (Eds): Physical Activity Fitness and Health: International Proceeding and consensus statement, Human Kinetics cham Piling (III), 1994, 77-88.

5. Gupta A, Sandhu JS, Koley S. Study on the physical fitness, spinal mobility and flexibility in football. Indian sport studies $2002 ; 6(1): 1-5$.

6. Esther $\mathrm{H}$ et al. The effect of age on physical fitness of deaf elementary school children. Pediatric exercise science 2007; 19:267-278.

7. Habbinen A. Association of physical fitness with health related quality of life in finish young men. Journal of health and quality of life outcomes 2010; 10:1477-7525.

8. Haga M. Physical fitness in children with high competence is different from that in children with low motor competence. Journal of physiological therapy 2009; 89(10):1089-1097.

9. Marry FW. Physical Fitness of 10 grade White and Black female students of Northern High School. Completed Research in Health. Physical Education \& Recreation 1982; 24(19):53.

10. Iahinone M, Mito R, Satio K. Physical activity fitness and health: Obesity and Lifestyle in Mamaica. International collaboration in community health $2004 ; 1267: 39-50$ 